\title{
Electropolymerization of Brilliant Cresyl Blue on Carbon Ionic Liquid Electrode and Electrocatalytic Application for the Voltammetric Determination of Ascorbic Acid
}

\author{
Xia Li, Qingjuan Niu, Guangjiu Li, Tianrong Zhan and Wei Sun* \\ Shandong Provincial Key Laboratory of Biochemical Analysis, College of Chemistry and Molecular \\ Engineering, Qingdao University of Science and Technology, Qingdao 266042, P. R. China
}

\begin{abstract}
Azul de cresil brilhante (BCB) foi eletropolimerizado sobre a superfície de um eletrodo de carbono líquido iônico (CILE) por voltametria cíclica de varredura na faixa de potencial de $-0,5$ a 1,0 V. CILE foi preparado usando o 1-etil-3-metil-imidazólio tetrafluoroborato ([EMIM] $\mathrm{BF}_{4}$ ) como modificador. Um filme polimerico estável de BCB foi obtido no CILE com aparecimento de um par de picos redox. As características do filme PBCB foram estudadas por diversos métodos tais como, microscopia eletrônica de varredura (SEM), espectroscopia de impedância eletroquímica (EIS) e voltametria cíclica. O eletrodo modificado apresentou excelente resposta eletrocatalítica para ácido ascórbico com o aumento das respostas eletroquímicas. Sob condições ótimas, uma boa resposta voltamétrica linear foi obtida no intervalo $2,0 \times 10^{-5}-3,0 \times 10^{-3} \mathrm{~mol} \mathrm{~L}^{-1}$, com limite de detecção de $6,5 \mu \mathrm{mol} \mathrm{L} \mathrm{L}^{-1}(3 \sigma)$.

Brilliant cresyl blue (BCB) was electropolymerized on the surface of a carbon ionic liquid electrode (CILE) by cyclic voltammetric sweep in the potential range from -0.5 to $1.0 \mathrm{~V}$. CILE was prepared by using 1-ethyl-3-methyl-imidazolium tetrafluoroborate ([EMIM] $\left.\mathrm{BF}_{4}\right)$ as modifier. The stable polymer film of BCB was obtained on the CILE and a pair of redox peaks appeared. The characteristics of PBCB film was studied by different methods such as scanning electron microscopy (SEM), electrochemical impedance spectroscopy (EIS) and cyclic voltammetry. This modified electrode showed excellent electrocatalytic response to ascorbic acid with the increase of the electrochemical responses. Under the optimal conditions a good linear voltammetric response could be obtained over the range of $2.0 \times 10^{-5}-3.0 \times 10^{-3} \mathrm{~mol} \mathrm{~L}^{-1}$ and the detection limit was got as $6.5 \mu \mathrm{mol} \mathrm{L}-1(3 \sigma)$.
\end{abstract}

Keywords: brilliant cresyl blue, ascorbic acid, carbon ionic liquid electrode, electropolymerization

\section{Introduction}

In recent years ionic liquids (ILs) have been widely used in the fields of electrochemistry and electroanalysis due to the specific characteristics including negligible vapor pressure, wide potential windows, good ionic conductivity, extraction and catalytic ability. ${ }^{1}$ Wei et $a .^{2}{ }^{2}$ reviewed the recent progresses of ILs in the field of electrochemical sensors. ILs have been proved to be an efficient modifier and binder in place of the traditional non-conductive organic binders in the preparation of carbon paste electrode (CPE). Carbon ionic liquid electrode (CILE) has exhibited many specific advantages including low cost, easy fabrication, simple preparation procedure, wide potential windows,

*e-mail: sunwei@qust.edu.cn high rates of electron transfer, good anti-fouling ability and inherent catalytic activity. ${ }^{3}$ Electrochemical detection based on CILE as working electrode has been widely investigated in recent years. Zheng and co-workers ${ }^{4,5}$ investigated the electrochemical behaviors of calcium dobesilate and rutin on the CILE. Li et al. ${ }^{6}$ constructed a prussian blue modified CILE for the nonenzyme hydrogen peroxide sensor. A hydroxylapatite modified CILE was also prepared for the simultaneous determination of ultratrace lead and cadmium. ${ }^{7}$ Our group also applied different kinds of CILEs for the investigation on the electrochemical behaviors of some electroactive substances including DNA and proteins..$^{8-11}$

Polymer modified electrode prepared by electropolymerization is commonly used in the chemically modified electrode. By carefully controlling the electrochemical 
conditions, a layer of polymer can be in situ formed on the electrode surface with controllable thickness, high conductivity and good stability. Many electroactive dyes have been electropolymerized on the working electrode. For example, Yang et al. ${ }^{12}$ prepared poly(safranine T) films on the graphite electrode and investigated the electrocatalytic effect to dopamine. Balamurugan et al. ${ }^{13}$ prepared poly(brilliant cresyl blue) and poly(5-amino-2-napthalenesulfonic) composite modified electrode by the electrochemical polymerization. Vostiar et al. ${ }^{14}$ electropolymerized toluidine blue on glassy carbon electrode for the construction of an amperometric urea biosensor. Karyakin et al. ${ }^{15}$ prepared poly(methylene blue) modified electrode for the electrocatalytic oxidation of NADH.

Ascorbic acid (AA) is an important molecule with many applications in the fields of medicine, veterinary science, food and drink industry. Various methods have been proposed for AA determination such as HPLC, capillary zone electrophoresis (CZE), spectrophotometry and electroanalysis. ${ }^{16-18}$ Due to its large overpotential and electrode fouling, AA can not be directly determined by the electrochemical method on conventional bare electrode. ${ }^{19,20}$ So the chemically modified electrode has been widely constructed to accelerate the electrochemical reaction and decrease the overpotential. Various kinds of modifiers such as chloranil, ${ }^{21}$ fisetin $^{22}$ and $\mathrm{C}_{60}$-[dimethyl-( $\beta$-cyclodextrin $\left.)\right]_{2} / \mathrm{Nafion}^{23}$ etc, were reported for the electrode modification in the literature.

In this paper a poly(brilliant cresyl blue) (PBCB) film was synthesized on the surface of CILE by cyclic voltammetry. Brilliant cresyl blue (BCB) is a cationic quinine-imide dye with a planar and rigid structure, and it has been proven to possess promising properties as a redox catalyst. BCB has been used as a fluorescent indicator for measurements across biological membranes. ${ }^{24} \mathrm{~A}$ sensor for hemoglobin based on PBCB electrodeposited on platinum electrode has also been reported..$^{25}$ By electropolymerization of $\mathrm{BCB}$ on the CILE surface, a layer of conducting film was formed, which exhibited improved electrochemical performance. The electrocatalytic behaviors of PBCB/CILE to the oxidation of AA were carefully investigated, which provided a sensitive method for AA and its drug formulation detection.

\section{Experimental}

\section{Reagents}

Brilliant cresyl blue (BCB, Shanghai Reagent Company), 1-ethyl-3-methyl- imidazolium tetrafluoroborate ([EMIM] $\mathrm{BF}_{4}$, Hangzhou Chemer Chemical Limited Company), ascorbic acid (AA, Shanghai Kangjiu Chemical Reagent Limited Company) and graphite powder (average particle size $30 \mu \mathrm{m}$, Shanghai Colloid Chemical Plant) were used as received. A $0.1 \mathrm{~mol} \mathrm{~L}^{-1}$ phosphate buffer solution (PBS) was used as the supporting electrolyte. All the other chemicals were of analytical reagent grade and double-distilled water was used in all the experiments.

\section{Apparatus}

A CHI 750B electrochemical analyzer (Shanghai $\mathrm{CH}$ Instrument, China) was used for all the electrochemical experiments with a traditional three-electrode system composed of a CILE or PBCB/CILE as working electrode, a platinum wire as auxiliary electrode and a saturated calomel electrode (SCE) as reference electrode. Scanning electron microscopy (SEM) was obtained on a JSM-6700F scanning electron microscope (Japan Electron Company).

\section{Preparation of polymer modified electrode}

CILE was prepared by mixing $1.6 \mathrm{~g}$ of graphite powder, $100 \mu \mathrm{L}$ of [EMIM] $\mathrm{BF}_{4}$ and $400 \mu \mathrm{L}$ of liquid paraffin in an agate mortar by hand. The prepared homogeneous carbon paste was tightly packed into a glass tube $(\Phi=4 \mathrm{~mm})$ and a copper wire was introduced into the other end for the electrical contact. The surface of CILE was smoothed on a weighing paper prior to use. For BCB polymerization, the CILE was immersed into a $0.1 \mathrm{~mol} \mathrm{~L}^{-1} \mathrm{pH} 7.0 \mathrm{PBS}$ contained $3.0 \mathrm{mmol} \mathrm{L}^{-1} \mathrm{BCB}$ and $0.1 \mathrm{~mol} \mathrm{~L}^{-1} \mathrm{KCl}$. Then cyclic voltammetry was performed between the potential range from -0.5 to $1.0 \mathrm{~V}$ for 50 cycles with the scan rate of $100 \mathrm{mV} \mathrm{s}^{-1}$. Electrode with electropolymerized layers was rinsed with PBS and distilled water for three times, and dried at room temperature for further usage.

\section{Results and Discussion}

\section{Electropolymerization of brilliant cresyl blue on CILE}

Figure 1 showed the cyclic voltammograms of polymer film growth in electrolytic solution, which was consisted of $3.0 \mathrm{mmol} \mathrm{L}^{-1} \mathrm{BCB}, 0.1 \mathrm{~mol} \mathrm{~L}^{-1} \mathrm{pH}$ 7.0 PBS and $0.1 \mathrm{~mol} \mathrm{~L}^{-1}$ $\mathrm{KCl}$. From the first cycle it can be seen that a pair of welldefined redox peaks appeared with anodic and cathodic peaks at $-0.26 \mathrm{~V}$ and $-0.16 \mathrm{~V}$, respectively, which were attributed to the oxidation and the reduction of $\mathrm{BCB}$. With the further increase of the potential cycles, a new pair of redox peaks appeared with anodic and cathodic peaks located at $0.13 \mathrm{~V}$ and $-0.03 \mathrm{~V}$, respectively. At the same time the new redox peak currents increased gradually. The result indicated that the polymer film was formed on the surface of CILE and its thickness increased with the number of potential cycles. As 
indicated by Maleki et al., ${ }^{26}$ the presence of IL in the carbon paste electrode exhibited not only high adherence of the graphite particles, but also the $\pi$-electron interaction of the IL layers with the $\pi$-electron system of graphite. CILE had been demonstrated to have the advantages such as wide potential windows, high electron transfer rates and good anti-fouling ability. A layer of IL was also formed on the surface of CILE, which had the inherent catalytic ability. So the presence of IL as modifier in the carbon paste electrode provided an inherent catalytic interface for $\mathrm{BCB}$ polymerization to take place. According to the former reports about the polymerization of azine monomer, ${ }^{27,28}$ the electro-oxidation of BCB monomer proceeds and yields some highly reactive species like cation radicals, which initiate the electropolymerization of the monomer. The gradually increase of the redox peaks in the cyclic voltammogram indicated the gradually conversion of $\mathrm{BCB}$ into its polymeric product, and a thin blue colored film was formed on the surface of CILE.

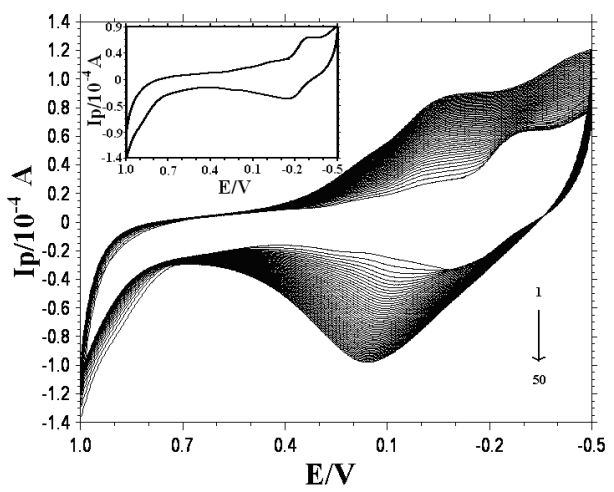

Figure 1. Cyclic voltammograms of $3.0 \mathrm{mmol} \mathrm{L}^{-1} \mathrm{BCB}$ electropolymerized on the CILE with the sweep cycles from 1 to 50 . Inset is cyclic voltammogram of the first circle with the scan rate of $100 \mathrm{mV} \mathrm{s}^{-1}$.

The optimal conditions for the growth of PBCB film were investigated. Electropolymerization of $\mathrm{BCB}$ requires a high potential for the irreversible oxidation of the monomer. If the potential is too high, over-oxidation of the polymer will take place. So the potential range was optimized and the redox peak currents of PBCB reached the maximum in the potential range from $-0.5 \mathrm{~V}$ to $1.0 \mathrm{~V}$. The redox peak currents of $\mathrm{PBCB}$ increased with the increase number of the potential cycles. However, when the number of potential cycles was up to 50, there were no obvious increase of the redox peak currents. From the experiments it was found that the redox peak currents of $\mathrm{PBCB}$ increased with the increase of scan rate in the range from $30 \mathrm{mV} \mathrm{s}^{-1}$ to $200 \mathrm{mV} \mathrm{s}^{-1}$. After considering the time factor in the experiments, the number of potential cycles and scan rate were selected as 50 and $100 \mathrm{mV} \mathrm{s}^{-1}$, respectively. By controlling the experimental conditions, a series of PBCB modified CILE were fabricated in parallel for further use.

\section{Surface morphology}

Scanning electron microscopy (SEM) was used to characterize and compare the morphology of different modified electrodes with the results shown in Figure 2. It can be seen that an uneven and discontinuous fault appeared on the surface of CPE (Figure 2a). While a uniform and no separated carbon layers could be observed on the CILE surface (Figure 2b). Since [EMIM] $\mathrm{BF}_{4}$ was a hydrophilic ionic liquid with high viscosity, it could fill into the layer of graphite powder and bridge the isolated carbon flask, so a flat surface could be obtained. Figure $2 c$ showed the SEM image of PBCB/CILE where a layer of compact films appeared, which indicated that BCB was successfully electropolymerized on the surface of CILE with a polymer film formed.

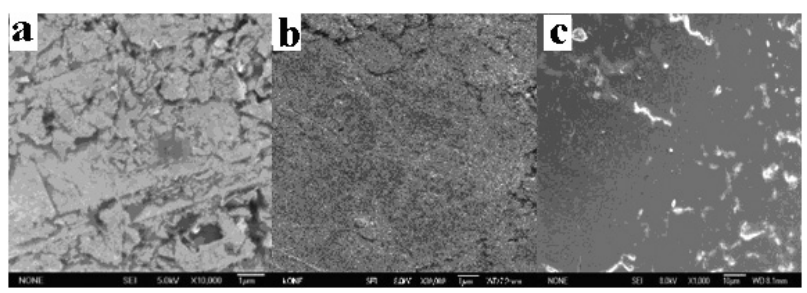

Figure 2. SEM morphologies of CPE (a), CILE (b) and PBCB/CILE (c).

\section{Electrochemical characteristics of the modified electrode}

Electrochemical impedance spectroscopy (EIS) is a useful technique to monitor the impedance changes of the electrode surface during the modification process. The semicircle diameters of Nyquist plot reflects the electron transfer resistance (Ret), from the electron transfer of the redox probe $\left[\mathrm{Fe}(\mathrm{CN})_{6}\right]^{3-14}$. The semicircular part at higher frequencies corresponds to the electron transfer limited process and the linear part at lower frequencies corresponds to the diffusion process. The interfacial characteristic of the PBCB/CILE was studied by EIS in a $0.1 \mathrm{~mol} \mathrm{~L}^{-1} \mathrm{KCl}$ solution contained the redox couples of $1.0 \mathrm{mmol} \mathrm{L}^{-1}\left[\mathrm{Fe}(\mathrm{CN})_{6}\right]^{3-14}$. Figure $3 \mathrm{~A}$ showed the EIS of different electrodes with the frequencies swept from $10^{4}$ to $0.1 \mathrm{~Hz}$. Here $\mathrm{Z}^{\prime}$ and $\mathrm{Z}^{\prime \prime}$ are the real and imaginary parts of experimental data. Then the Randles circuit is used to fit the impedance spectra. The Ret value of CPE was estimated as $308.1 \Omega$ (curve a) and that of CILE decreased to $203.13 \Omega$ (curve b), which was due to the presence of high ionic conductive IL in the CPE. The Ret value of PBCB/CILE decreased further and a straight line appeared (curve c), which indicated that the presence of PBCB film exhibited good conductivity and the electron transfer rate at the electrode/ solution interface was greatly increased.

Figure 3B showed typical cyclic voltammograms of the modified electrodes in $\mathrm{K}_{3}\left[\mathrm{Fe}(\mathrm{CN})_{6}\right]$ and $\mathrm{KCl}$ solution. 
On the CILE a pair of well-defined redox peaks appeared (curve b) with peak-to-peak separation $(\Delta \mathrm{Ep})$ at $0.102 \mathrm{~V}$ (vs. SCE), which was much smaller than the $\Delta$ Ep value $(0.161 \mathrm{~V})$ of the CPE (curve a), and the redox peak currents also increased greatly, which may be due to the high ionic conductive IL present in the CPE. On the PBCB/CILE, the redox peak current further increased when more reversible electrochemical responses appeared (curve c), due to the presence of high conductive polymer film on the CILE surface that further accelerated the electron transfer rate of the redox probe.
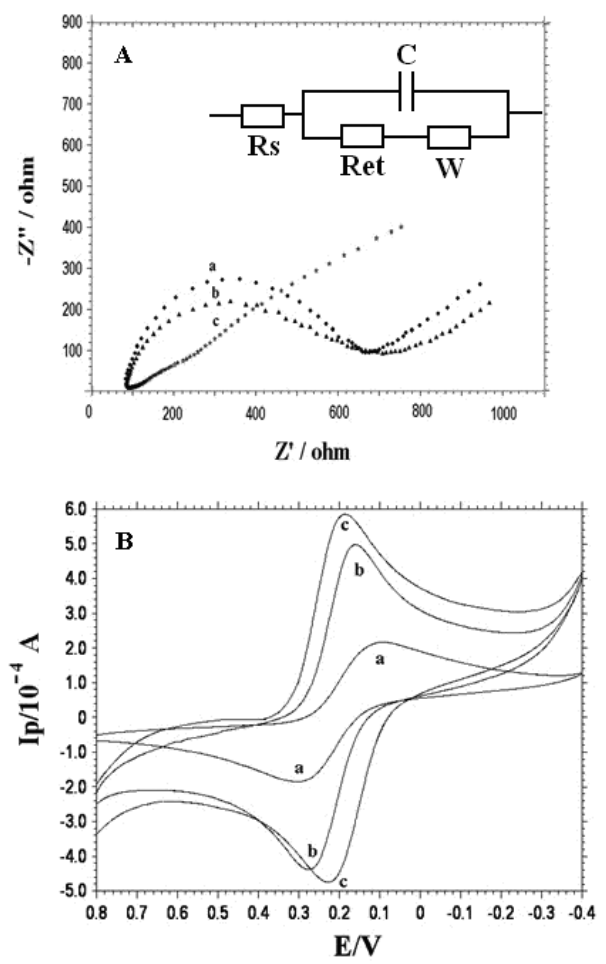

Figure 3. (A) Electrochemical impedance spectroscopy of CPE (a), CILE (b) and PBCB/CILE (c) in a $0.1 \mathrm{~mol} \mathrm{~L}^{-1} \mathrm{KCl}$ solution containning $1.0 \mathrm{mmol} \mathrm{L}^{-1}\left[\mathrm{Fe}(\mathrm{CN})_{6}\right]^{3-14}$ with frequencies swept from $10^{4}$ to $0.1 \mathrm{~Hz}$. Inset is the Randles circuit model in the cell. (B) Cyclic voltammograms of CPE (a), CILE (b) and PBCB/CILE (c) in solution of $5.0 \times 10^{-4} \mathrm{~mol} \mathrm{~L}^{-1}$ $\mathrm{K}_{3}\left[\mathrm{Fe}(\mathrm{CN})_{6}\right]+0.5 \mathrm{~mol} \mathrm{~L}^{-1} \mathrm{KCl}$ at scan rate of $100 \mathrm{mV} \mathrm{s}^{-1}$.

\section{Electrochemical behaviors of $A A$ on the PBCB/CILE}

Figure 4 shows cyclic voltammograms of $3.0 \mathrm{mmol} \mathrm{L}^{-1}$ AA in $0.1 \mathrm{~mol} \mathrm{~L}^{-1}$ PBS pH 6.5 on different electrodes. On the CPE, AA exhibited an oxidation peak located at $432 \mathrm{mV}$ (vs. SCE) with the oxidation peak current at $15.28 \mu \mathrm{A}$ (curve a). On the CILE the oxidation potential appeared at $338 \mathrm{mV}$ (vs. SCE) with the oxidation peak current at $36.1 \mu \mathrm{A}$ (curve b). The overpotential decreased $94 \mathrm{mV}$ and the oxidation peak potential increased 1.5 times, indicating the superiority of CILE to CPE. The presence of IL in the CPE showed the inherent catalytic ability due to the specific characteristics of IL. While on the PBCB/CILE the oxidation peak potential reached $286 \mathrm{mV}$ ( $v s$. SCE) with a peak current of $73.2 \mu \mathrm{A}$ (curve c). Compared with that of CPE and CILE, a decrease of overpotential of 146 and $52 \mathrm{mV}$ ( vs. SCE) towards more negatively direction was observed when the peak current increased for about 4.7 and 2.03 times, respectively. It is wellknown that the increase of peak current and the decrease of overpotential are the characteristics of the electrocatalytic reaction. The experimental results further testified the superiority of PBCB/CILE to CPE and CILE, indicating that PBCB film on the electrode surface increased the ability of electron transfer at the interface of electrode/solution and catalyzed the electro-oxidation reaction of AA.

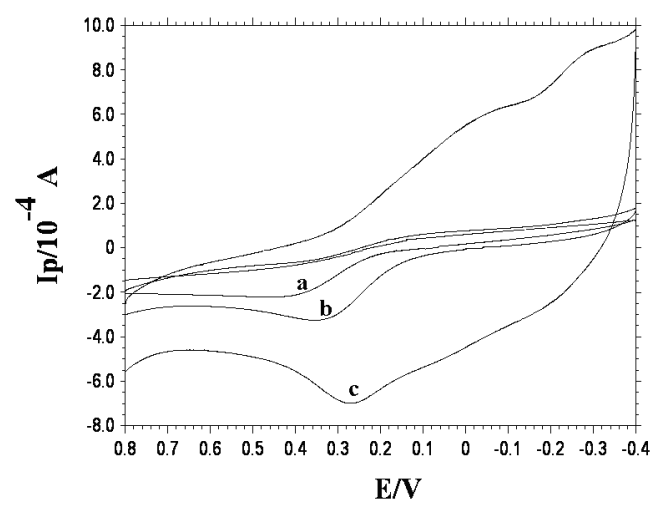

Figure 4. Cyclic voltammograms of $3.0 \times 10^{-3} \mathrm{~mol} \mathrm{~L}^{-1} \mathrm{AA}$ on $\mathrm{CPE}$ (a), CILE (b) and PBCB/CILE (c) in $0.1 \mathrm{~mol} \mathrm{~L}^{-1} \mathrm{PBS} \mathrm{pH} 6.5$.

Cyclic voltammograms of AA with different scan rates were further investigated. With the increase of scan rate the oxidation peak current increased with the positively movement of the oxidation peak potential. A linear relationship of oxidation peak currents (Ipa) of AA with scan rate was constructed with the linear regression equation as $\operatorname{Ipa}(\mu \mathrm{A})=$ $0.940+9.073 v\left(\mathrm{~V} \mathrm{~s}^{-1}\right)(\gamma=0.996)$, indicating an adsorptioncontrolled electrode process. As for an adsorption-controlled irreversible electrode process, the electrochemical parameters such as charge transfer coefficient $(\alpha)$ and the electrode reaction rate constant $\left(k_{s}\right)$ can be calculated by exploring the relationship of oxidation peak potential with scan rate. ${ }^{29}$ The relationship of Epa with $\ln v$ was constructed with the linear regression equation $\mathrm{Epa}(\mathrm{V})=0.256+0.122 \ln v(\gamma=0.997)$. From the slope and the intercept, the values of $\alpha$ and $k_{s}$ were calculated as 0.53 and $0.875 \mathrm{~s}^{-1}$, respectively.

\section{Optimal of experimental conditions}

The optimal $\mathrm{pH}$ for AA oxidation was carefully investigated and the results were shown in Figure 5A. It can be seen that the maximum value of oxidation peak current appeared at $\mathrm{pH} 6.5$, so this value was selected throughout 
the experiments. Since the electrode process was adsorptioncontrolled, the accumulation time for AA was investigated. It can be seen that the peak current reached its maximum at $30 \mathrm{~s}$ (Figure 5B). So $30 \mathrm{~s}$ of accumulate time was used in the following procedure.
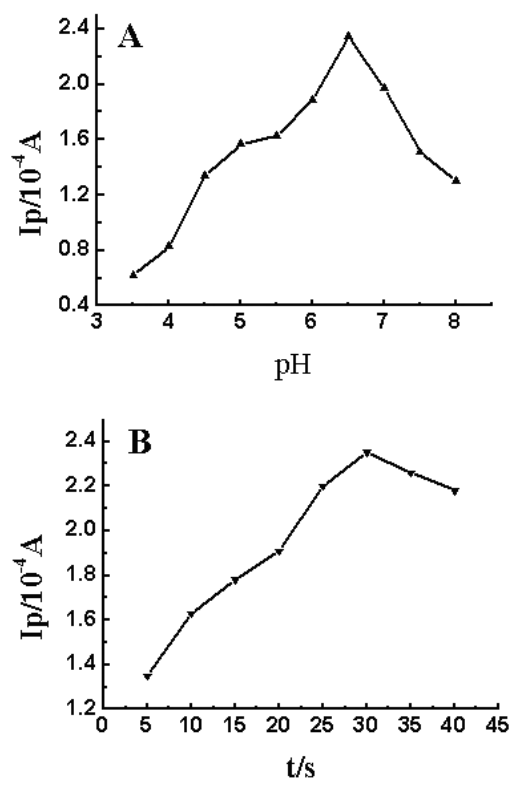

Figure 5. (A) Effect of $\mathrm{pH}$ buffer on the oxidation peak current of $3.0 \times 10^{-3} \mathrm{~mol} \mathrm{~L}^{-1} \mathrm{AA}$. (B) Effect of accumulation time on the peak current of $3.0 \times 10^{-3} \mathrm{~mol} \mathrm{~L}^{-1} \mathrm{AA}$ in PBS pH 6.5 with the scan rate of $100 \mathrm{mV} \mathrm{s}^{-1}$.

\section{Calibration curve}

Under the optimal conditions differential pulse voltammetry (DPV) was used for the sensitive determination of AA. Figure 6 showed the DPV curves of different concentrations of AA on PBCB/CILE in PBS pH 6.5. The DPV oxidation peak currents increased linearly with AA concentration in the range from $2.0 \times 10^{-5}$ to $3.0 \times 10^{-3} \mathrm{~mol} \mathrm{~L}^{-1}$ with the linear regression equation as $\operatorname{Ipa}(\mu \mathrm{A})=0.318+$ $0.522 \mathrm{C}\left(\mathrm{mol} \mathrm{L}^{-1}\right)(\gamma=0.999)$, with a detection limit of $6.5 \mu \mathrm{mol} \mathrm{L}-1(3 \sigma)$.

The reproducibility and stability of PBCB/CILE were further investigated. A relative standard deviation (RSD) of $1.96 \%$ was obtained for seven successive determinations of $2.0 \times 10^{-5} \mathrm{~mol} \mathrm{~L}^{-1} \mathrm{AA}$ in PBS $\mathrm{pH} 6.5$, which indicated that PBCB/CILE showed good reproducibility. The modified electrode was stored at $4{ }^{\circ} \mathrm{C}$ when not in use and $98.1 \%$ of the initial current response was retained after 2 weeks storage. After one month storage, the peak current response decreased about $7.9 \%$. Moreover, five PBCB modified electrodes were prepared by the same procedure independently and the relative standard deviation (RSD) for the determination of $2.0 \times 10^{-5} \mathrm{~mol} \mathrm{~L}^{-1} \mathrm{AA}$ was calculated as $3.5 \%$, which indicated the modified electrode had good repeatability.

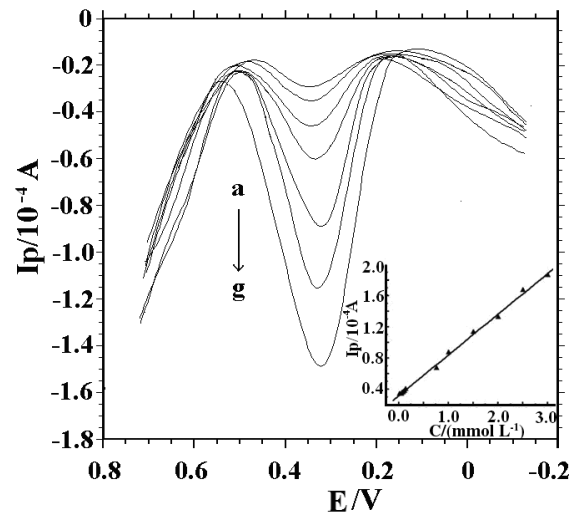

Figure 6. Differential pulse voltammograms of $\mathrm{PBCB} / \mathrm{CILE}$ at different AA concentrations (from a to g are $5.0 \times 10^{-5}, 8.0 \times 10^{-5}, 1.0 \times 10^{-4}, 5.0 \times 10^{-4}$, $8.0 \times 10^{-4}, 1.0 \times 10^{-3}, 3.0 \times 10^{-3} \mathrm{~mol} \mathrm{~L}^{-1}$, respectively). Inset is the linear relationship of anodic peak currents and AA concentrations.

\section{Interference study}

The influences of some coexisting substances such as inorganic ions and organic compounds on the determination of $3.0 \mathrm{mmol} \mathrm{L}^{-1} \mathrm{AA}$ were investigated with the results listed in Table 1 . These substances may be commonly existed in the biological samples. It can be seen that few of them had influence on the determination and the PBCB/CILE showed good selectivity.

Table 1. Influences of coexisting substances on the determination of $3.0 \times 10^{-3} \mathrm{~mol} \mathrm{~L}^{-1} \mathrm{AA}$

\begin{tabular}{lcc}
\hline Coexisting substance & Concentration & Relative error / (\%) \\
\hline Citric acid & $40.0 \mathrm{mg} \mathrm{L}^{-1}$ & -0.27 \\
Glucose & $40.0 \mathrm{mg} \mathrm{L}^{-1}$ & 0.16 \\
L-Cysteine & $40.0 \mathrm{mg} \mathrm{L}^{-1}$ & -1.36 \\
L-Arginine & $40.0 \mathrm{mg} \mathrm{L}^{-1}$ & -2.97 \\
L-Glutamine & $40.0 \mathrm{mg} \mathrm{L}^{-1}$ & 1.25 \\
DNA & $10.0 \mathrm{mg} \mathrm{L}^{-1}$ & 4.98 \\
RNA & $40.0 \mathrm{mg} \mathrm{L}^{-1}$ & -1.82 \\
Epinephrine & $2.0 \times 10^{-5} \mathrm{~mol} \mathrm{~L}^{-1}$ & -2.18 \\
$\mathrm{Zn}^{2+}$ & $4.0 \times 10^{-5} \mathrm{~mol} \mathrm{~L}^{-1}$ & -3.64 \\
$\mathrm{~K}^{+}$ & $1.0 \times 10^{-2} \mathrm{~mol} \mathrm{~L}^{-1}$ & 6.37 \\
$\mathrm{Ca}^{2+}$ & $4.0 \times 10^{-5} \mathrm{~mol} \mathrm{~L}^{-1}$ & -4.91 \\
$\mathrm{Cl}^{-}$ & $1.0 \times 10^{-2} \mathrm{~mol} \mathrm{~L}^{-1}$ & 0.15 \\
\hline
\end{tabular}

DNA: Deoxyribonucleic acid, RNA: Ribonucleic acid.

\section{Analytical application and recovery test}

To assess the analytical application of the proposed method, a Vitamin C tablet, which was purchased from Shandong Luoxin Pharmaceutical Co. Ltd. (060221) with the specified amount of $0.1 \mathrm{~g}$ AA per tablet, was determined 
Table 2. Determination of AA in Vitamin C tablet $(n=5)^{*}$

\begin{tabular}{lcccccc}
\hline Sample & Specified / g & Detected /g & $\begin{array}{c}\text { Added / } \\
\left(10^{-4} \mathrm{~mol} \mathrm{~L}^{-1}\right)\end{array}$ & $\begin{array}{c}\text { Detected / } \\
\left(10^{-4} \mathrm{~mol} \mathrm{~L}^{-1}\right)\end{array}$ & RSD / (\%) & Recovery / (\%) \\
\hline 1 & 0.1 & 0.096 & 5.00 & 4.89 & 1.63 & 97.8 \\
2 & 0.1 & 0.092 & 5.00 & 5.06 & 2.01 & 101.2 \\
3 & 0.1 & 0.094 & 5.00 & 4.82 & 1.47 & 96.4 \\
\hline
\end{tabular}

*average of 5 parallels detection.

by standard addition method. The determination results were shown in Table 2. It can be seen that the proposed method was sensitive with a recovery range of $96.4 \%-101.2 \%$, indicating the practical application of this modified electrode.

\section{Conclusions}

Electrochemical polymerization of $\mathrm{BCB}$ on the surface of carbon ionic liquid electrode was performed and the properties of the resulted polymer films modified electrode were investigated. Experimental results exhibited that $\mathrm{BCB}$ had been polymerized on the electrode surface with excellent electrochemical performances. The polymer film on the electrode showed good electrocatalytic ability to the oxidation of AA and the electrochemical behaviors of AA on PBCB/CILE was carefully investigated. Under the optimal conditions, a linear relationship of the oxidation peak current and the AA concentration was obtained within the range from $2.0 \times 10^{-5}$ to $3.0 \times 10^{-3} \mathrm{~mol} \mathrm{~L}^{-1}$ by differential pulse voltammetry, and the method was further applied to AA drug sample detection with satisfactory results.

\section{Acknowledgments}

We are grateful to the financial support of the Shandong Province Natural Science Foundation (ZR2009BL017).

\section{References}

1. Musameh, M.; Wang, J.; Anal. Chim. Acta 2008, 606, 45.

2. Wei, D.; Ivaska, A.; Anal. Chim. Acta 2008, 607, 126.

3. Maleki, N.; Safavi, A.; Sedaghati, F.; Tajabadi, F.; Anal. Biochem. 2007, 369, 149.

4. Zheng, J. B.; Zhang, Y.; Yang, P. P.; Talanta 2007, 73, 920.

5. Zhang, Y.; Zheng, J. B.; Talanta 2008, 77, 325.

6. Li, Y. H.; Liu, X. Y.; Zeng, X. D.; Liu, Y.; Liu, X. S.; Wei, W.Z.; Luo, S. L.; Microchim. Acta 2009, 165, 393.

7. Li, Y. H.; Liu, X. Y.; Zeng, X.D.; Liu, Y.; Liu, X. T.; Wei, W. Z.; Luo, S. L.; Sens. Actuators, B 2009, 139, 604.

8. Sun, W.; Yang, M. X.; Jiao, K.; Anal. Bioanal. Chem. 2007, $389,1283$.
9. Sun, W.; Li, Y. Z.; Duan, Y. Y.; Jiao, K.; Biosens. Bioelectron. 2008, 24, 994.

10. Sun, W.; Li, Y. Z.; Yang, M. X.; Liu, S. F.; Jiao, K.; Electrochem. Commun. 2008, 10, 298.

11. Sun, W.; Li, Y.Z.; Gao, H. W.; Jiao, K.; Microchim. Acta 2009 , 165, 313.

12. Yang, Q. X.; Zhang, M. F.; Li, G. B.; Zhang, Y.; Chin. J. Anal. Lab. 2007, 26, 72 .

13. Balamurugan, A.; Chen, S. M.; J. Solid State Electrochem. 2010, 14,35 .

14. Vostiar, I.; Tkac, J.; Sturdik, E.; Gemeiner, P; Bioelectrochemistry 2002, 56, 113.

15. Karyakin, A. A.; Karyakina, E. E.; Schuhmann, W.; Varfolomeyev, S. D.; Electroanalysis 1994, 6, 821.

16. Albrecht, J. A.; Schafer, H. W.; J. Liq. Chromatogr. 1990, 13, 2623.

17. Chiari, M.; Nesi, M.; Carrea, G.; Righetti, P. G.; J. Chromatogr. 1993, 645, 197.

18. Fei, J. J.; Luo, L. M.; Hu, S. S.; Gao, Z. Q.; Electroanalysis 2004, 16, 319.

19. Raoof, J. B.; Ojani, R.; Kiani, A.; J. Electroanal. Chem. 2001, 515,45 .

20. Zen, J. M.; Tsai, D. M.; Kumar, A. S.; Electroanalysis 2002 , $15,1171$.

21. Ojani, R.; Raoof, J. B.; Zamani, S.; Electroanalysis 2005, 17, 1740.

22. Golabi, S. M.; Irannejad, L.; Electroanalysis 2005, 17, 985.

23. Wei, M.; Li, M. X.; Li, N. Q.; Gu, Z. N.; Zhou, X. H.; Electroanalysis 2002, 14, 135.

24. Teuber, M.; Rogner, M.; Berry, S.; Biochim. Biophys. Acta 2001, 1506, 31 .

25. Dong, S. J.; Zhu, Y. M.; Song, S. H.; J. Electroanal. Chem. 1989, 275, 233.

26. Maleki, N.; Safavi, A.; Tajabadi, F. Anal. Chem. 2006, 78, 3820.

27. Chen, X. X.; Wang, Y.; Hu, S. S.; Microchim. Acta 2008, 161, 255.

28. Malinauskas,A.; Niaura, G.; Bloxham, S.; Ruzgas, T.; Gortony,L.; J. Colloid Interface Sci. 2000, 230,122.

29. Laviron, E.; J. Electroanal. Chem. 1979, 101, 19.

Submitted: June 16, 2010 Published online: October 14, 2010 